\title{
Rewiring a secondary metabolite pathway towards itaconic acid production in Aspergillus niger
}

Abeer H. Hossain ${ }^{1,3^{*}}$, An Li ${ }^{2}$ Anja Brickwedde², Lars Wilms' ${ }^{1}$, Martien Caspers ${ }^{2}$, Karin Overkamp ${ }^{1}$ and Peter J. Punt ${ }^{1}$

\begin{abstract}
Background: The industrially relevant filamentous fungus Aspergillus niger is widely used in industry for its secretion capabilities of enzymes and organic acids. Biotechnologically produced organic acids promise to be an attractive alternative for the chemical industry to replace petrochemicals. Itaconic acid (IA) has been identified as one of the top twelve building block chemicals which have high potential to be produced by biotechnological means. The IA biosynthesis cluster (cadA, $m t t A$ and $m f s A$ ) has been elucidated in its natural producer Aspergillus terreus and transferred to A. niger to enable IA production. Here we report the rewiring of a secondary metabolite pathway towards further improved IA production through the overexpression of a putative cytosolic citrate synthase citB in a A. niger strain carrying the IA biosynthesis cluster.
\end{abstract}

Results: We have previously shown that expression of cadA from A. terreus results in itaconic acid production in A. niger AB1.13, albeit at low levels. This low-level production is boosted fivefold by the overexpression of $m t t A$ and $m f_{S} A$ in itaconic acid producing AB1.13 CAD background strains. Controlled batch cultivations with AB1.13 CAD + MFS + MTT strains showed increased production of itaconic acid compared with AB1.13 CAD strain. Moreover, preliminary RNA-Seq analysis of an itaconic acid producing AB1.13 CAD strain has led to the identification of the putative cytosolic citrate synthase citB which was induced in an IA producing strain. We have overexpressed citB in a AB1.13 CAD + MFS + MTT strain and by doing so hypothesize to have targeted itaconic acid production to the cytosolic compartment. By overexpressing citB in AB1.13 CAD + MFS + MTT strains in controlled batch cultivations we have achieved highly increased titers of up to $26.2 \mathrm{~g} / \mathrm{L}$ IA with a productivity of $0.35 \mathrm{~g} / \mathrm{L} / \mathrm{h}$ while no CA was produced.

Conclusions: Expression of the IA biosynthesis cluster in Aspergillus niger AB1.13 strain enables IA production. Moreover, in the AB1.13 CAD strain IA production resulted in overexpression of a putative cytosolic citrate synthase citB. Upon overexpression of citB we have achieved titers of up to $26.2 \mathrm{~g} / \mathrm{L}$ IA with a productivity of $0.35 \mathrm{~g} / \mathrm{L} / \mathrm{h}$ in controlled batch cultivations. By overexpressing citB we have also diminished side product formation and optimized the production pathway towards IA.

Keywords: Itaconic acid, Secondary metabolite, Controlled-batch cultivation, Citric acid, citB

\section{Background}

Global carbon emissions as a result of petroleum-based processing and products are forcing industries to look for alternative processing and production methods.

\footnotetext{
*Correspondence: abeer.hossain@ddna-biotech.com

1 Dutch DNA Biotech B.V, Utrechtseweg 48, 3704 HE Zeist,

The Netherlands

Full list of author information is available at the end of the article
}

Bio-based organic acid production promises to be an attractive alternative for the chemicals industry to replace petrochemicals and for the food industry as an food additive. For thousands of years humans have employed the help of microorganisms for the production of organic acids e.g. lactic acid and acetic acid [1]. More recently, filamentous fungi have stepped forward as potent producers of organic acids and the industrial producers of 
enzymes. Itaconic acid (IA) is a C-5 dicarboxylic acid that has been recognized by the US Department of Energy as one of the top 12 building block chemicals with high potential to be produced using biotechnology [2]. IA has a broad application potential in the chemicals industry as co-monomer in the production of polymers, surfactants and fibers (for review see [3]). Another application potential is in agriculture or medicine as a bioactive compound [4]. Since the 1960s, industrial production is facilitated by its natural producer Aspergillus terreus, a filamentous fungus, at a maximum production rate of $1.2 \mathrm{~g} / \mathrm{L} / \mathrm{h}$ and fermentations can reach a final titer of $86.2 \mathrm{~g} / \mathrm{L}$ [5]. Although higher IA levels have been reported in literature these have been reached under conditions that are not suitable for industrial application [6, 7]. Li et al. have previously proposed Aspergillus niger as a suitable production host for the industrial production of IA due to the hosts optimized pathways towards organic acids. Therefore, these researchers have successfully identified the IA biosynthesis cluster in Aspergillus terreus by using a clone based transcriptomics approach. This gene cluster consists of the cis-aconitate decarboxylase $(\operatorname{cadA})$, mitochondrial tricarboxylate transporter $(m t t A)$ and the major facilitator superfamily protein $(m f s A)$ (Fig. 1) [8]. Expression of cadA in $A$. niger resulted in IA production albeit at low levels [8-10]. This low production was increased by expressing $m f s A$ and $m t t A$ in an IA producing A. niger transformant (AB1.13 CAD 4.1). The resulting AB1.13 CAD + MFS3.9 and AB1.13 CAD + MTT 1.4 improved production by twofold [11]. In this research we have continued this work towards third generation IA production $A$. niger strains. In a first approach we reconstituted strains with the complete gene cluster. To identify other genes relevant for improving IA production in A. niger we have performed a preliminary RNA-Seq analysis to identify genes differentially expressed in relation to IA production. One of the identified genes encodes a putative cytosolic citrate synthase, of which overexpression resulted in improved IA production.

\section{Methods}

Strains, vector construction and transformation methods

All strains used in this study have an AB1.13 background [12] and are listed in Table 1. All strains are stored in $30 \%$ glycerol at $-80{ }^{\circ} \mathrm{C}$ and maintained on potato dextrose agar plates (BD, New Jersey, USA) or on agar containing minimal medium plates $(16 \mathrm{~g} / \mathrm{L}$ agar, $6 \mathrm{~g} / \mathrm{L}$ $\mathrm{NaNO}_{3}, 0.52 \mathrm{~g} / \mathrm{L} \mathrm{KCl}, 1.52 \mathrm{~g} / \mathrm{L} \mathrm{KH}_{2} \mathrm{PO}_{4}, 10 \mathrm{~g} / \mathrm{L}$ glucose, $0.0022 \mathrm{~g} / \mathrm{L} \mathrm{ZnSO}_{4} \times 7 \mathrm{H}_{2} \mathrm{O}, 0.0011 \mathrm{~g} / \mathrm{L} \mathrm{H}_{3} \mathrm{BO}_{3}, 0.0005 \mathrm{~g} / \mathrm{L}$ $\mathrm{MnCl}_{2} \times 4 \mathrm{H}_{2} \mathrm{O}, 0.0005 \mathrm{~g} / \mathrm{L} \mathrm{FeSO}_{4} \times 7 \mathrm{H}_{2} \mathrm{O}, 0.00017 \mathrm{~g} / \mathrm{L}$ $\mathrm{CoCl}_{2} \times 6 \mathrm{H}_{2} \mathrm{O}, 0.00016 \mathrm{~g} / \mathrm{L} \mathrm{CuSO}{ }_{4} \times 5 \mathrm{H}_{2} \mathrm{O}, 0.00015 \mathrm{~g} / \mathrm{L}$ $\mathrm{NaMoO}_{4} \times 2 \mathrm{H}_{2} \mathrm{O}, 0.005 \mathrm{~g} / \mathrm{L} \mathrm{Na} \mathrm{Na}_{2}$ EDTA and $0.5 \mathrm{~g} / \mathrm{L}$ $\mathrm{Mg}_{2} \mathrm{SO}_{4}$ ). Spore suspensions were prepared using physiological salt solution and stored at $4{ }^{\circ} \mathrm{C}$ for up to 1 year.

Transformations with $m t t A$ were performed using AB1.13 CAD + MFS 3.9 strain and citB was overexpressed in the resulting AB1.13 CAD + MFS + MTT \#49 strain. The $m t t A$ gene construct was the same as used in the previous study of Li et al. [11] and introduced by co-transformation with the pAN-7 plasmid, that contains the hph

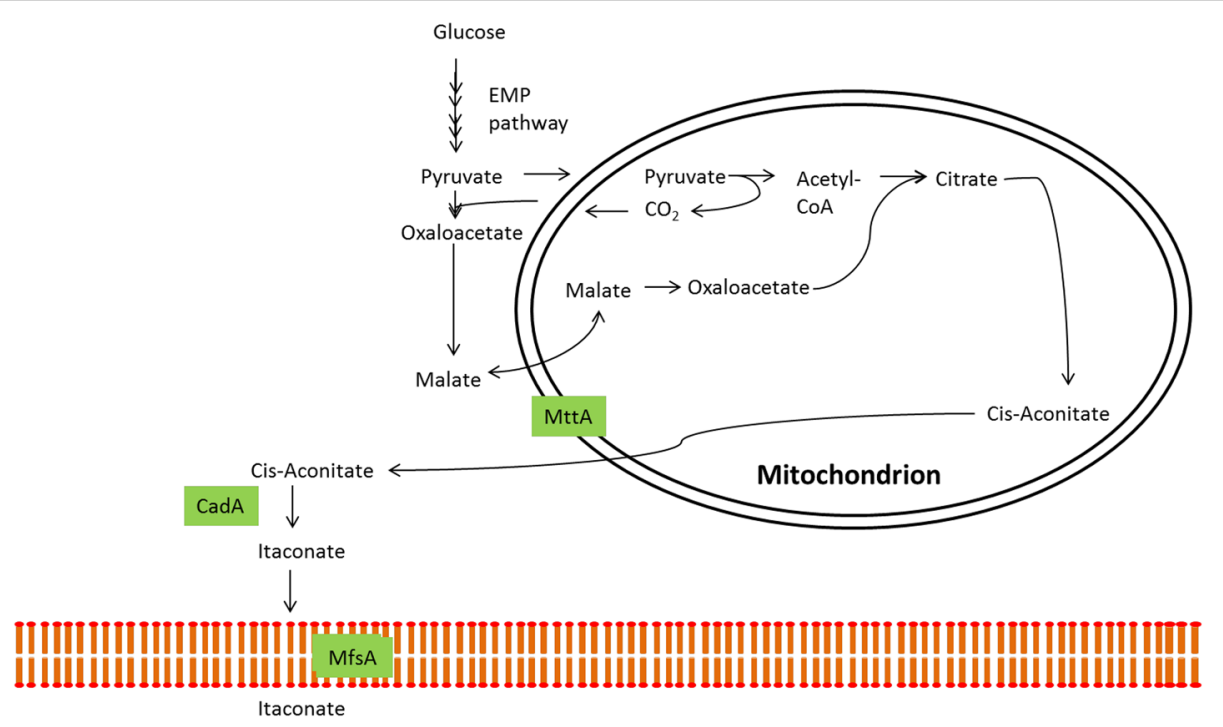

Fig. 1 Itaconic acid production pathway in Aspergillus terreus. The itaconic acid biosynthesis pathway in Aspergillus terreus. Glucose is converted to pyruvate through glycolysis. Pyruvate is converted to acetyl-CoA that together with oxaloacetate forms citric acid and start the TCA cycle. MttA transports cis-aconitate from the mitochondrion into the cytosol where CadA facilitates the conversion of cis-aconitic acid to itaconic acid and concomitantly MfsA transports itaconic acid out of the cell. Note that only direct pathway steps towards IA production are shown 
Table 1 List of strains used during this study

\begin{tabular}{lll}
\hline Strain/transformant & Abbreviation & Strain description \\
\hline AB1.13 CAD 4.1 & CAD 4.1 & Selected pyrG + transformant of cadA expressing transformant (CAD10.1) of AB1.13: [13] \\
AB1.13 CAD + MFS 3.9 & MFS 3.9 & Selected mfSA expressing transformant of CAD10.1: [1 1] \\
AB1.13 AD + MFS + MTT & AB1.13 \#08; & Selected mttA expressing transformants of AB1.13 CAD + MFS 3.9 \\
$\# 08 ;$ & AB1.13\#49; & \\
$\# 49 ;$ & AB1.13 \#63 & \\
$\# 63$ & CitB \#77; & Selected citB overexpressing transformants of AB1.13 CAD + MFS + MTT \#49 \\
AB1.13 CAD + MFS + MTT + CitB & CitB \#99; & \\
$\# 77 ;$ & CitB \#101; & \\
$\# 99 ;$ & CitB \#113 & \\
$\# 101 ;$ & & \\
$\# 113$ &
\end{tabular}

resistance gene, in an ratio of 1:10 $(10 \mu \mathrm{g}$ construct:1 $\mu \mathrm{g}$ marker). The transformed protoplasts were plated on MM agar plates containing sorbitol and Hygromycin B (15 g/L agar, 6 g/L NaNO${ }_{3}, 0.52 \mathrm{~g} / \mathrm{L} \mathrm{KCl}, 1.52 \mathrm{~g} / \mathrm{L} \mathrm{KH}_{2} \mathrm{PO}_{4}, 1 \%$ glucose, $0.5 \mathrm{~g} / \mathrm{L} \mathrm{MgSO}_{4}, 0.022 \mathrm{~g} / \mathrm{L} \mathrm{ZnSO}_{4} \cdot 7 \mathrm{H}_{2} \mathrm{O}, 0.011 \mathrm{~g} / \mathrm{L}$ $\mathrm{H}_{3} \mathrm{BO}_{3}, 0.005 \mathrm{~g} / \mathrm{L} \mathrm{MnCl} \mathrm{Mn}_{2} \cdot 4 \mathrm{H}_{2} \mathrm{O}, 0.005 \mathrm{~g} / \mathrm{L} \mathrm{FeSO} \cdot 7 \mathrm{H}_{2} \mathrm{O}$, $0.0017 \mathrm{~g} / \mathrm{L} \quad \mathrm{CoCl}_{2} \cdot 6 \mathrm{H}_{2} \mathrm{O}, 0.0016 \mathrm{~g} / \mathrm{L} \quad \mathrm{CuSO}_{4} \cdot 5 \mathrm{H}_{2} \mathrm{O}$, $0.0015 \mathrm{~g} / \mathrm{L} \mathrm{NaMoO}_{4} \cdot 2 \mathrm{H}_{2} \mathrm{O}, 0.05 \mathrm{~g} / \mathrm{L} \mathrm{Na}_{2}$ EDTA, $218.6 \mathrm{~g} / \mathrm{L}$ sorbitol and $200 \mathrm{mg} / \mathrm{L}$ hygromycin $\mathrm{B}$ ) and incubated at $33{ }^{\circ} \mathrm{C}$ for up to 1 week until colonies were visible.

To establish overexpression of citB a PCR amplified copy of this gene was generated with the primers citB-F3$\mathrm{ATG}+\mathrm{BsmBI}$ (5'-CGTCTCCCATGCCCGACATCGCAT CCAAC-3') and citB-R1 + NcoI (3'-ATCCGTCAAAGCG AGAGTGGTACC-5') using genomic Aspergillus niger DNA as template. The resulting PCR fragment was digested with $B s m \mathrm{BI} / \mathrm{NcoI}$ and the fragment was inserted into an pABgpd1 containing the $A$. niger gpdA expression signals thus establishing the $c i t B$ expression vector pABgpdI-citB [14]. This construct was co-transformed with pAN8-1, that harbours the phleomycin resistance marker [15], in an ratio of 1:10 ( $1 \mu \mathrm{g}$ marker: $10 \mu \mathrm{g}$ construct). Transformed protoplasts were plated on MM agar plates containing sorbitol and phleomycin $(50 \mathrm{mg} / \mathrm{L})$.

\section{Fermentations}

Controlled batch-cultivations were performed on 51 scale benchtop New Brunswick Scientific fermenters (BioFlo 3000 ) at $33{ }^{\circ} \mathrm{C}$. Starting $\mathrm{pH}$ was 3.5 after inoculation and medium was allowed to naturally acidify till $\mathrm{pH} 2.3$ and then kept at $\mathrm{pH} 2.3$ by addition of $4 \mathrm{M} \mathrm{KOH}$. Dissolved oxygen (DO) tension was $25 \%$ at moment of inoculation and DO dropped till $20 \%$ and kept at $20 \%$. The system was calibrated with $100 \%$ sterile air as $100 \%$ DO and $100 \% \mathrm{~N}_{2}$ as $0 \%$ DO. The fermenter was inoculated by $72 \mathrm{~h}$ old $100 \mathrm{ml}$ baffled shake flask cultures containing $1.0 \times 10^{8}$ spores. Medium composition for fermentation and pre-culture $(\mathrm{M} 12+\mathrm{Cu})$ are listed in Table 2 [13].
Table 2 Composition of medium $12+\mathrm{Cu}$, which is used as production medium for IA (Adapted from Li et al. [13])

\begin{tabular}{ll}
\hline Component & Final concentration (g/L) \\
\hline $\mathrm{NH}_{4} \mathrm{SO}_{4}\left[\left(\mathrm{NH}_{4}\right)_{2} \mathrm{SO}_{4}\right]$ & 2.36 \\
$\mathrm{KH}_{2} \mathrm{PO}_{4}$ & 0.11 \\
$\mathrm{MgSO}_{4} \times 7 \mathrm{H}_{2} \mathrm{O}$ & 0.5 \\
$\mathrm{CuSO}_{4} \times 5 \mathrm{H}_{2} \mathrm{O}$ & 0.005 \\
$\mathrm{FellSO}_{4} \times 7 \mathrm{H}_{2} \mathrm{O}$ & 0.0006 \\
$\mathrm{ZnSO}_{4} \times 7 \mathrm{H}_{2} \mathrm{O}$ & 0.0006 \\
$\mathrm{NaCl}_{\mathrm{CaCl}} \times 2 \mathrm{H}_{2} \mathrm{O}$ & 0.074 \\
$\mathrm{GlucOSe}$ & 0.13 \\
\hline
\end{tabular}

\section{Colony PCR}

Successful integration of $m t t A$ constructs was determined with colony PCR [16].

\section{HPLC}

Metabolite analysis was performed using a WATERS e2695 separations module equipped with an Aminex $\mathrm{HPX}-87 \mathrm{H}$ column (Bio-Rad) and $5 \mathrm{mM} \mathrm{H}_{2} \mathrm{SO}_{4}$ as eluent. Detection of peaks occurred simultaneously by a refractive index detector (WATERS 2414) and a dualwavelength detector (WATERS UV/Vis 2489). Data processing was done with Empower Pro software (Empower 2 Software, copyright 2005-2008, Waters Corporation, Milford, Massachusetts, USA).

\section{Microplate based transformant screening}

Plates carrying transformed cells were allowed to grow and sporulate for 1-2 weeks after which individual colonies were transferred to a selective MM plate. Individual colonies from this plate were each streaked on a separate selective MM plate to isolate single colonies that in turn was used to inoculate a $1 \mathrm{~mL}$ liquid culture in a 96-wells deepwell plate containing M12 + Cu. This 96-wells plate 
was incubated for $72 \mathrm{~h}$ at $33{ }^{\circ} \mathrm{C}$ and 850 RPM. Supernatant was filtered over a $0.22 \mu \mathrm{M}$ filter and analyzed on the HPLC for IA production. Colonies that showed promising results in terms of IA production were grown on plates to prepare spore suspensions.

\section{Southern blotting}

Shake flask $(500 \mathrm{~mL})$ cultures containing $100 \mathrm{~mL}$ $\mathrm{M} 12+\mathrm{Cu}$ were inoculated with $1.0 \times 10^{7}$ spores and grown for 3 days at $33{ }^{\circ} \mathrm{C}$ and 125 RPM. Upon harvesting the mycelia were washed with demi water and immediately frozen in liquid nitrogen. The frozen mycelia were ground to a fine powder using a sterile mortar and pestle. Three hundred microgram of ground mycelia were sampled per strain and DNA isolation occurred using the mag kits from LGC (LGC, Queens Road, Teddington, Middlesex, TW11, OLY, UK) and per manufacturers instruction. Quality of isolated DNA was tested by running on $0.8 \%$ agarose gel. Four microgram genomic DNA was digested per strain with $B g l \mathrm{II}$ and $M l u \mathrm{I}$ (New England Biolabs) and run on agarose gel o/n. Blotting occurred on Nitrocellulose N+ blotting paper (Amersham Biosciences) using SSC (175.5 $\mathrm{g} \mathrm{NaCl}$ and $88.2 \mathrm{~g}$ $\mathrm{Na}$-Citrate in $1 \mathrm{~L} ; 20 \times$ stock) solution. After blotting the membranes were treated in UV-chamber to cross-link DNA. Labeling and detection were performed using the DIG Easy Hyb labeling and detection kit for Southern blotting purposes (Roche Life Sciences) per the manufacturers instructions.

\section{IA toxicity assay}

Shakeflasks $(500 \mathrm{~mL})$ were prepared with $100 \mathrm{~mL}$ $\mathrm{M} 12+\mathrm{Cu}$ supplemented with the following IA concentrations: $0,10,20,30$ and $40 \mathrm{~g} / \mathrm{L}$. $\mathrm{pH}$ was adjusted to 2.3 by addition of $\mathrm{KOH} / \mathrm{H}_{2} \mathrm{SO}_{4}$. The flasks were inoculated with $1 \mathrm{ml}$ of overnight grown pre-culture. After 7 days the mycelium was harvested and the biomass was determined by measuring the dry weight.

\section{RNA isolation and transcriptome analyses}

Two $500 \mathrm{~mL}$ baffled shakeflasks containing $100 \mathrm{~mL}$ $\mathrm{M} 12+\mathrm{Cu}$ were inoculated with $1.0 \times 10^{6}$ spores $/ \mathrm{ml}$ of $\mathrm{AB} 1.13 \mathrm{WT}$ and CAD 4.1 and incubated at $33^{\circ} \mathrm{C}$ and 125 RPM for $48 \mathrm{~h}$. After cultivation the mycelium was harvested, washed with distilled water and frozen in liquid $\mathrm{N}_{2}$. The mycelium was ground with mortar and pestle to a fine powder and RNA extraction proceeded using the Trizol method. Quality control was checked on $1 \times$ MOPS/6 \% Formaldehyde agarose gels and stained with ethidium bromide.

Service XS in Leiden, NL performed digital gene expression profiling experiments based on RNA-Seq with an Illumina HiSeq 2000 System. Approximately
8-32 $\mathrm{M}$ unfiltered paired-end (PE) reads (99 bp/read on $\sim 320$ bp cDNA inserts) were obtained. Reads were trimmed of the first two bases of the $5^{\prime}$ end because these bases showed an aberrantly low GC content. The reads were then further filtered, such that all quality phred scores after filtering are at least 22 , with a read-length of at least 40 bases. Around $70-80 \%$ of the bases passed these criteria (including a $2 \%$ loss because of clipping). After filtering the \#PE-reads/samples were 10.9 and $10.0 \mathrm{M}$ for the CAD and WT sample respectively.

Reads were aligned to the 20 contigs in a FastA file of the Aspergillus niger reference genome (from http:// www.ebi.ac.uk/ena). Source EMBL annotations were converted to GFF format. The EMBL data appeared to be derived from multiple sources with different feature tags. These were converted to one uniform GFF format that could be accepted by our third-party software (consistent gene_ids across all contigs). Missing gene definitions (e.g. for CAD) were inserted. The reads were aligned to the reference genome using software based on a Burrows-Wheeler Transform (BWT) algorithm. A mismatch rate of $4 \%$ was allowed for the alignment. The maximum insertion length was 3 . The maximum deletion length was 3. All samples had more than $85 \%$ of the reads aligned, resulting in SAM alignment files. Gene expression was measured as the number of aligned reads to reference genes and was normalized to RPKM values (Reads per kb per million reads; Mortazavi et al. [17]). Full analysis will be published elsewhere (Hossain et al. manuscript in preparation).

\section{Results}

\section{Expression of IA biosynthesis cluster}

Based on previous results we established in our research that expression of the putative dicarboxylic acid exporter MfsA and a mitochondrial transporter MttA, both encoded by genes in the IA gene cluster in an $A$. niger strain carrying the cis-aconitate decarboxylase, resulted in increased IA levels [11]. The positive effect of overexpression of the dicarboxylic acid transporter was also confirmed in $A$. terreus [18]. Interestingly, different results were obtained in similar research recently published by van der Straat et al. [9]. More detailed analysis of the data revealed that in the latter research, a codonoptimized gene copy was used, based on an incorrectly annotated gene model, resulting in an unspliced intron in the gene sequence used (Additional file 1), explaining why expression of this gene copy did not result in increased IA secretion.

In our previous results we analyzed a small number of strains that could carry all three genes of the IA gene cluster. However, none of the strains analyzed showed 
increased IA levels compared to the parental strain containing only the cadA plus $m t t A$ gene [11]. In a further attempt to generate $A$. niger strains with all three genes of the cluster we now introduced $m t t A$ gene copies in strain AB1.13 CAD + MFS 3.9, carrying cadA and $m f s A$ [11]. Presence of $m t t A$ gene was confirmed in 68 out of 92 transformants by performing colony PCR. Based on the results obtained during microtiter plate screening in many of the transformants increased IA levels were observed (data not shown). From a selection of these 68 transformants ten strains were selected for further analysis in shake flasks. As shown in Fig. 2a and b apparently different classes of transformants were obtained. Those that perform at the same level as the parental strain (blue bars), those that perform 1.5-2.0 $\times$ better than the parental strain (yellow bars) and mutants that perform $5 \times$ better than the parental strain (red bars). Citric acid (CA) production increases when either $m f s A$ or $m t t A$ genes are expressed separately in a cadA background. But when both genes are expressed simultaneously CA production decreases again. Interestingly, the highest producers of IA AB1.13 CAD + MFS + MTT \#49 and \#63 strains are amongst the lowest $\mathrm{CA}$ producing transformants. For further analysis two strains with the highest level of IA were selected (AB1.13 \#49 and \#63) alongside with the AB1.13 \#08 strain which showed intermediate improvement in IA production (Fig. 2a yellow bars). As shown in Fig. 3a also in controlled batch cultivation the AB1.13 \#49 and \#63 strains showed clearly increased IA titers, productivity and yield compared to the AB1.13 \#08 and the parental AB1.13 CAD + MFS 3.9 strain [11], which produced comparable levels (Table 4). In the controlled batch cultivation AB1.13 \#49 showed a superior IA titer $(11.72 \mathrm{~g} / \mathrm{L})$ compared to the \#63 strain $(9.52 \mathrm{~g} / \mathrm{L})$. Also the productivity of \#49 $(0.08 \mathrm{~g} / \mathrm{L} / \mathrm{h})$ and yield $(0.16 \mathrm{~g} / \mathrm{g})$ are higher than the \#63 strain $(0.05 \mathrm{~g} / \mathrm{L} / \mathrm{h}$ and $0.13 \mathrm{~g} / \mathrm{g})$. The levels of CA produced by strain \#49 $(13.17 \mathrm{~g} / \mathrm{L})$ and \#63 (18.02 g/L) are an indicator that there is ample precursor available for conversion to IA and thus improvement of IA production.

\section{IA toxicity}

The obtained IA levels in these transformants are quite promising, but for commercial application considerably higher titers and yields would be required. As shown in Fig. 3b, during fermentation of the two high IA producing strains less glucose is consumed compared to the lower IA producer (AB1.13 \#08), whereas biomass and product formation ceased. As this retarded growth could be a consequence of the fact that IA is regarded to be mildly anti-microbial [4], the effect of IA on the growth of $A$. niger was tested.
As shown in Fig. 4 the growth of $A$. niger is already hampered at concentrations of $10 \mathrm{~g} / \mathrm{L}$ IA in the extracellular medium. At even higher concentrations (20, 40 and $75 \mathrm{~g} / \mathrm{L}$ ) the detrimental effects of IA on growth become more evident. Based on this result we hypothesize that IA toxicity may indeed limit its production in $A$. niger.

\section{Transcriptome analysis of an IA producing A. niger strain using RNA-Seq}

Increased levels of IA in the culture medium have shown a clear growth effect (Figs. 3, 4). Apparently, production of this novel metabolite in A. niger could result in considerable effects on fungal metabolism. Therefore we have performed a preliminary transcriptome analysis comparing mRNA samples from two day old shake flask cultures of the wild-type $A$. niger AB1.13 and low IA producing strain CAD 4.1. Two technical replicate samples of each strain were sequenced and differential expression analysis of the RNA sequence data was carried out to identify those organic acid pathway genes showing increased or decreased expression in the CAD 4.1 strain. In Additional file 1 the expression levels of all genes with a potential role in organic acid biosynthesis pathway are shown. The genes were selected based on extensive sequence homology of the encoded proteins with experimentally validated S. cerevisiae counterparts [19]. As shown in this table, in $A$. niger multiple genes encoding enzymes with putative citrate synthase activity are present. In silico predictions indicate that different members of this protein family are targeted to different cellular compartments. Our expression data suggest that in the WT strain these activities are mainly expressed from genes encoding mitochondrial protein, whilst in the CAD 4.1 strain genes encoding cytosolic proteins are expressed. It is evident that a gene encoding a putative cytosolic citrate synthase $(c i t B)[20,21]$ is induced in the CAD 4.1 strain.

Upon closer examination, the $c i t B$ gene is tightly clustered and part of a secondary metabolite cluster that consists of genes encoding the subunits of a fatty acid synthase, a regulation gene, a major facilitator transporter, a cytosolic cadA-like protein and a dienelactone hydrolase that are all induced together in the CAD 4.1 strain (Additional file 1). Based on these results we propose that this gene cluster encode genes constituting a biosynthetic pathway for a metabolite which is a fatty acid derived organic acid. Interestingly, literature research on A. niger secondary metabolites [22] reveal that $A$. niger is capable of producing alkyl-itaconic acids, also known as tensyuic acid [23].

Further analysis of the $c i t B$ gene sequence revealed that unlike the canonical citrate synthase citA, the encoded $\mathrm{CitB}$ protein contains no predicted mitochondrial or other 

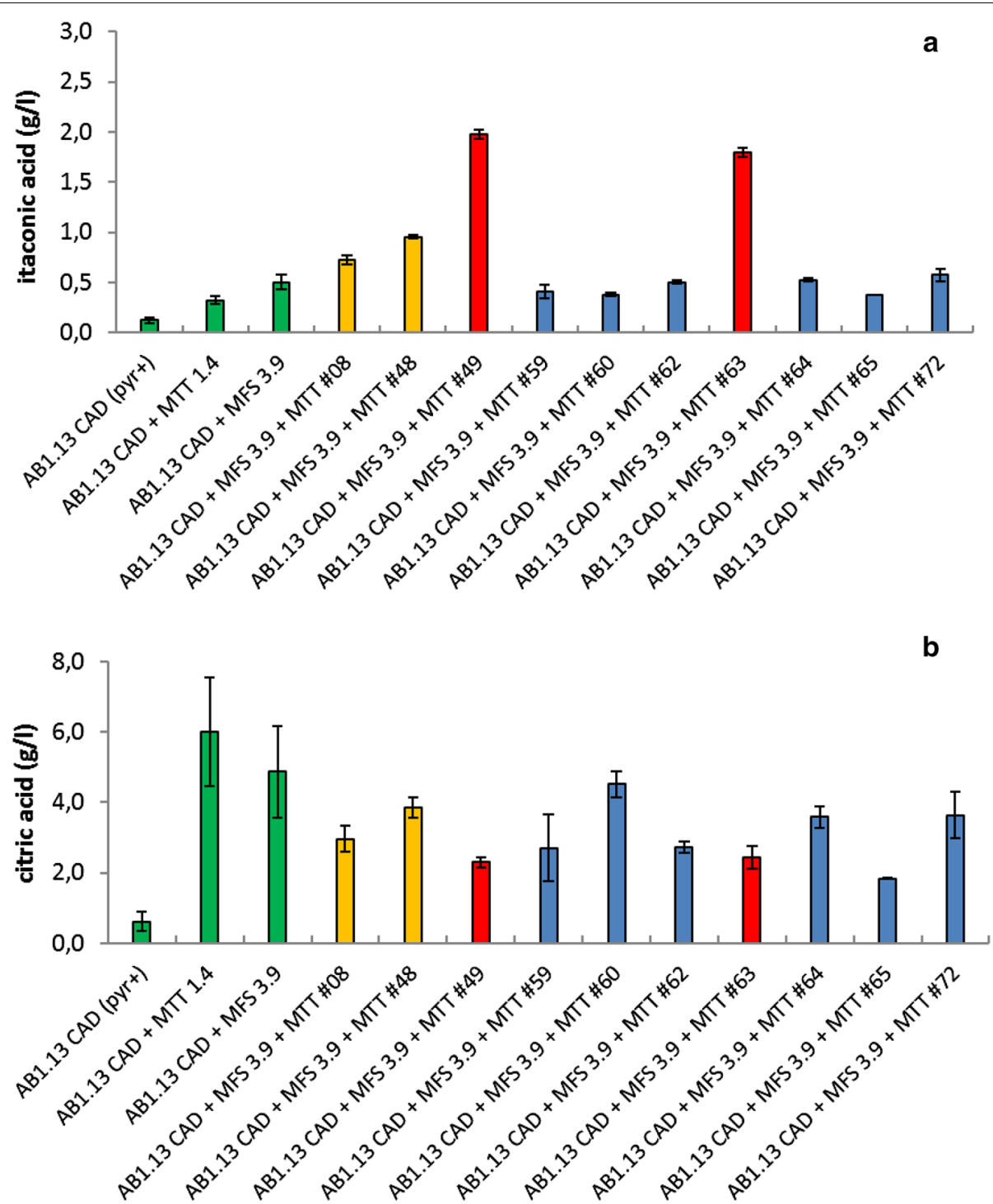

Fig. 2 Shake flask cultivation of itaconic acid producing A. niger transformants. HPLC analysis of shake flask experiment with AB1.13 itaconic acid producing transformants. Shake flasks were cultivated for 5 days prior to analysis. All strains were analyzed in triplicate. a Production of itaconic acid is compared amongst strains carrying CAD, CAD + MFS, CAD + MTT and CAD + MFS + MTT. Strains AB1.13 \#49 and \#63 have an fivefold improvement in IA production compared with the parental strain AB1.13 MFS 3.9. b Production of citric acid is compared amongst strains carrying CAD, CAD + MFS, CAD + MTT and CAD + MFS + MTT. The highest IA producers AB1.13 \#49 and \#63 produce the lowest amount of CA among all strains carrying the full IA biosynthesis cluster

targeting sequence and therefore is putatively targeted to the cytosol. Additional file 1 shows sequence comparison of the canonical CitA protein with the CitB protein that appears to show only $22 \%$ sequence similarity. More detailed phylogenetic analysis reveals that the proteins encoded by cit $A$ and citB are only distantly related to each other, quite possibly indicating different roles in metabolism (Fig. 5a). Interestingly, BLAST searches indicate that CitB orthologues are only present in a limited number of fungal strains. Of particular interest is that in A. terreus, from which the IA gene cluster originates, no $\mathrm{CitB}$ orthologue is present (Fig. 5a). Upon aligning the protein sequences of the PrpD-like proteins of A.niger with its orthologues in $A$. terreus it became clear that CadA and the upregulated CadA-like protein (An08g10870) are only distantly related (Fig. 5b). Upon closer examination of enzymes necessary for IA synthesis other than citrate synthase, i.e. aconitase and cis-aconitate decarboxylase, we found that only the $A$. niger acoA (An08g10530) gene is slightly upregulated in the CAD 4.1 strain (Additional file 1 ).

More recently Geiser et al. have reported an alternative IA biosynthetic pathway in the smut fungus Ustilago 


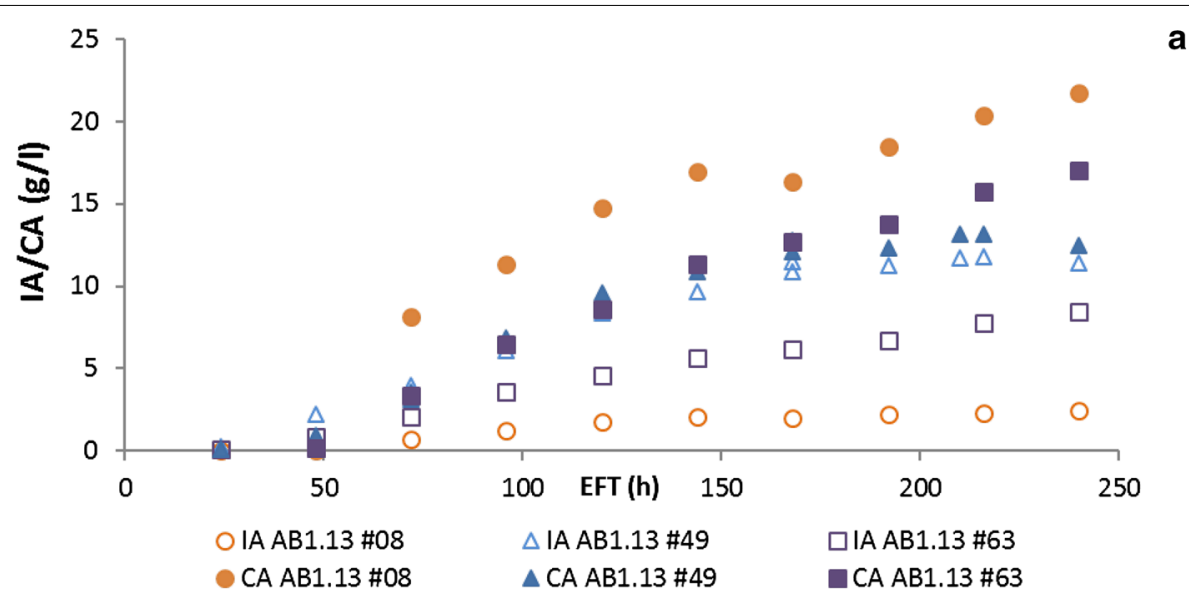

\section{a}

b

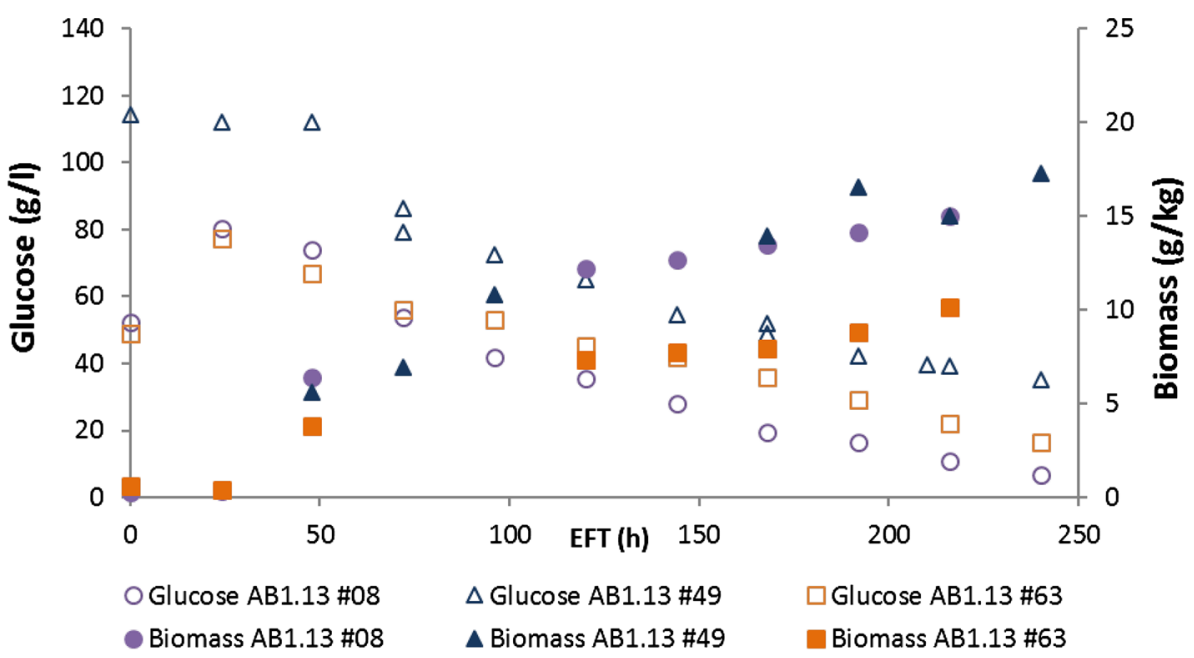

Fig. 3 Controlled batch cultivation of itaconic acid producing A. niger transformants. Controlled batch cultivation of AB1.13 strains carrying the full IA biosynthesis cluster. a HPLC analysis of organic acid production during controlled batch cultivations of AB1.13 strains \#08, \#49 and \#63. The highest IA titer is achieved by AB1.13 \#49 (11.74 g/L). AB1.13 \#08 produces the most CA ( $21.99 \mathrm{~g} / \mathrm{L})$ from all three strains and achieves the lowest IA titer (2.48 g/L). AB1.13 \#63 produces $9.52 \mathrm{~g} / \mathrm{L}$ IA and $18.03 \mathrm{~g} / \mathrm{L}$ CA. b Biomass development and glucose consumption during controlled batch cultivations of strains \#08, \#49 and \#63

maydis [24]. In this organism IA is produced via the unusual metabolite trans-aconitate which is converted to IA. Genes homologous to the two $U$. maydis genes involved in this alternative IA biosynthetic pathway tad 1 and adi1 are also present in $A$. niger (Additional file 1), however as shown in this table neither in the WT nor in the CAD 4.1 strain any of these genes is strongly expressed, indicating that this pathway is not actively used in Aspergillus niger.

\section{CitB overexpression}

Based on the results obtained from the transcriptome analysis it was considered that overexpression of citB could potentially facilitate the formation of citrate in the cytosol where it could be further processed into IA by the
CadA enzyme. Therefore, a citB expression vector was designed and introduced in AB1.13 CAD + MFS + MTT $\# 49$, being our best IA producer. In total, 129 colonies were identified on phleomycin containing selection plates as potential citB overexpressing transformants that were further analyzed in a microtiter plate screen. In the microtiter plate screen many of the obtained transformants produced more IA than the parental strain indicating a role of $c i t B$ in increasing IA production in strains carrying the full IA biosynthesis cluster (Fig. 6). Based on the screening results a number of strains with more than twofold increased IA levels were selected to be analyzed by Southern analysis to confirm the presence and number of additional $c i t B$ gene copies as well as to establish the 


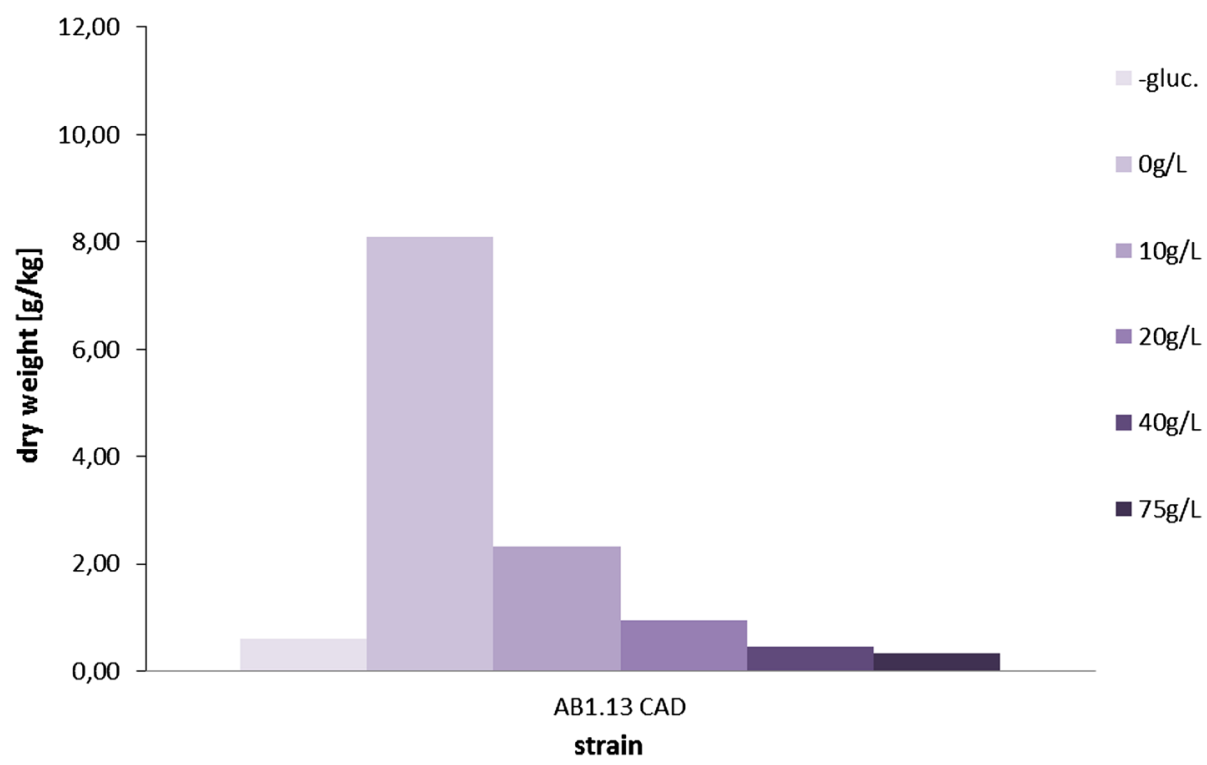

Fig. 4 Growth evaluation of A. niger in the presence of extracellularly added itaconic acid. Growth of AB1.13 CAD strain in M12+Cu supplemented with several concentrations of itaconic acid. Medium devoid of C-source is used as negative control. An extracellular concentration of $10 \mathrm{~g} / \mathrm{L}$ IA in the production medium results in an $75 \%$ decrease in biomass development. At $20 \mathrm{~g} / \mathrm{L}$ IA growth is at sub-inhibitory level and even higher concentrations of IA further deteriorate growth

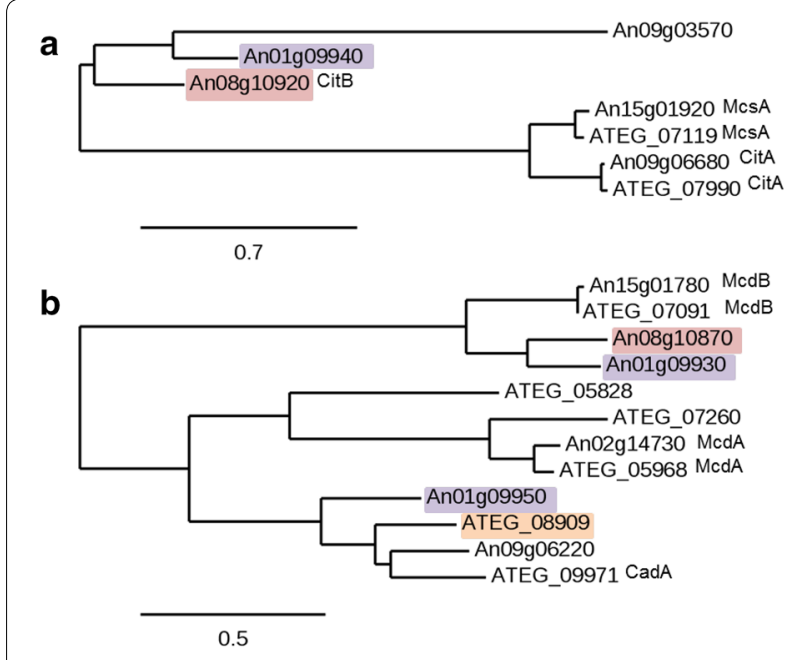

Fig. 5 Phylogenetic trees of selected pathway enzymes in A. niger and their orthologues in A. terreus. Phylogenetic trees of amino acid sequences of selected pathway enzymes in A. niger and their orthologues in A. terreus. The encoded Aspergillus niger proteins are designated with their corresponding An numbers (Anxxgxxxxx) and Aspergillus terreus proteins are designated with their corresponding ATEG numbers (ATEG_xxxxx). Proteins that are clustered together are shaded in the same colour throughout the separate classes. Phylogenetic trees were constructed using the phylogeny.fr online tool [38]. a Phylogenetic tree of known citrate synthase proteins and their orthologues in A. niger and A. terreus. Interestingly, the citrate synthase proteins from $A$. niger without predicted mitochondrial localization are clustered separately and no known orthologues are present in A. terreus. b Phylogenetic tree of CadA and predicted CadAlike enzymes in A. niger and $A$. terreus number of stably integrated $c a d A, m f s A$ and $m t t A$ gene copies (Table 3). Four of the selected citB overexpressing strains were used for further research under controlled fermentation conditions.

\section{Controlled batch-cultivations}

Controlled batch-cultivations were performed with the best four citB transformants CitB\#77, \#99, \#101 and \#113, together with their parental strain AB1.13 \#49. Maximum production of IA increased from $0.15 \mathrm{~g} / \mathrm{L} / \mathrm{h}$ for $\mathrm{AB} 1.13 \# 49$ to $0.35 \mathrm{~g} / \mathrm{L} / \mathrm{h}$ for $\mathrm{AB} 1.13 \mathrm{CitB} \# 99$ and $0.26 \mathrm{~g} / \mathrm{L} / \mathrm{h}$ for CitB\#113. CitB\#99 and \#113 reached final IA titers of 26.2 and $23.4 \mathrm{~g} / \mathrm{L}$ compared to a final titer of $12.96 \mathrm{~g} / \mathrm{L}$ for $\mathrm{AB} 1.13$ \#49. Interestingly CitB\#99 and \#113 do not secrete CA whereas AB1.13 \#49 secretes up to $8.91 \mathrm{~g} / \mathrm{L} \mathrm{CA}$ showing complete conversion of precursor CA to IA in CitB\#99 and \#113 (Fig. 7). The CitB \#77 and CitB\#101 strains, contrary to \#99 and \#113, still produce low amounts of CA with final titers of $1.96 \mathrm{~g} / \mathrm{L}$ (\#77) and $4.92 \mathrm{~g} / \mathrm{L}$ (\#101) (Fig. 8). Also the maximum production rate for IA is lower at $0.16 \mathrm{~g} / \mathrm{L} / \mathrm{h}(\# 77)$ and $0.11 \mathrm{~g} / \mathrm{L} / \mathrm{h}$ (\#101). The maximum productivity of AB1.13 \#49 is even higher than that of CitB \#101. Interestingly, the three high IA producing strains CitB\#77, \#99 and \#113 form less biomass during the course of the experiment than the less IA producing parental strain (\#49) and CitB\#101 (Figs. 7, 8). This observation highlights the potential antimicrobial effect of IA again in accordance to the results as shown in Fig. 4. 


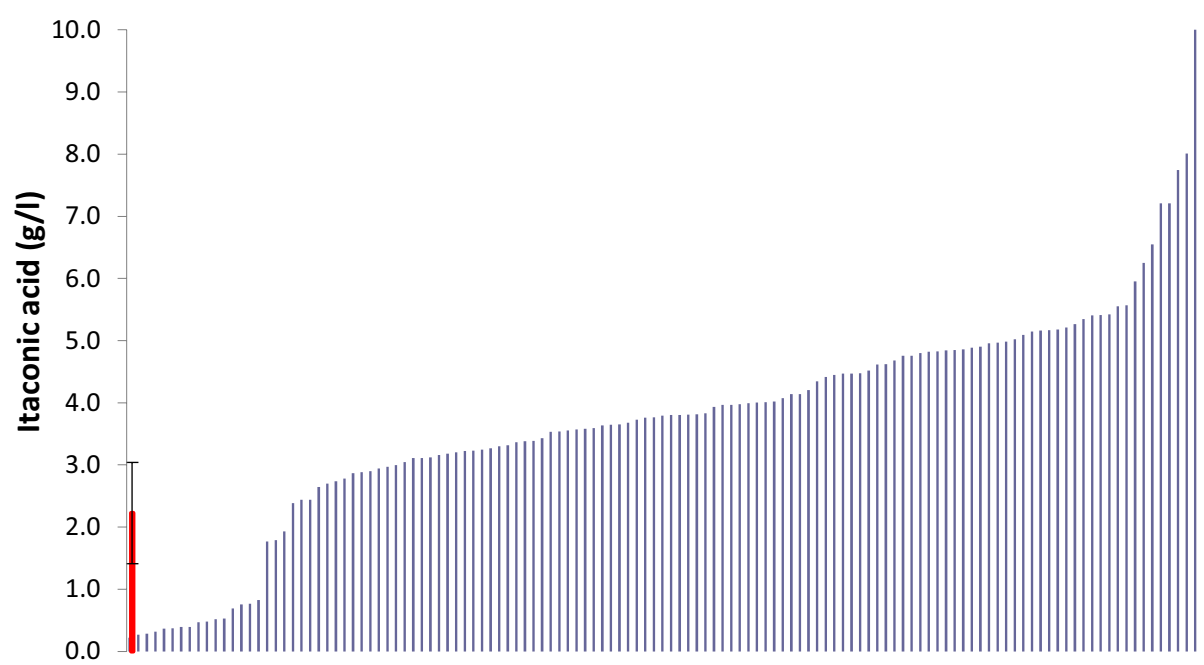

Fig. 6 Microtiter plate cultivation of citB overexpressing mutants. HPLC results from a five-day old microtiter plate culture of citB overexpressing mutants of AB1.13 CAD + MFS + MTT \#49.The parental control strain is indicated by a red bar with standard deviation. Out of 125 transformant colonies that were tested, 106 colonies produced more IA than the average produced by the parental strain

Table 3 Relative copy numbers of introduced genes

\begin{tabular}{llllc}
\hline Strain & \multicolumn{4}{l}{$\begin{array}{l}\text { Southern blot results (rel. } \\
\text { no. copies) }\end{array}$} \\
\cline { 2 - 5 } & cadA & mfsA & mttA & citB \\
\hline AB1.13 CAD 4.1 pyrG+ & 8 & 0 & 0 & 1 \\
AB1.13 CAD + MFS 3.9 & 8 & 2 & 0 & 1 \\
AB1.13 CAD + MTT 1.4 & 8 & 0 & $1-2$ & 1 \\
AB1.13 CAD + MFS + MTT \#49 & 8 & 2 & 1 & 1 \\
AB1.13 CAD + MFS + MTT \#63 & 8 & 2 & 0 & 1 \\
AB1.13 CAD + MFS + MTT \#08 & 8 & 2 & $1-3$ & 1 \\
AB1.13 CAD + MFS + MTT + CitB \#99 & 8 & 2 & 1 & 10 \\
AB1.13 CAD + MFS + MTT + CitB \#113 & 8 & 2 & 1 & 3 \\
AB1.13 CAD + MFS + MTT + CitB \#77 & 8 & 2 & 1 & 7 \\
AB1.13 CAD + MFS + MTT + CitB \#101 & 8 & 2 & 1 & 3 \\
\hline
\end{tabular}

\section{Discussion}

Organic acid production in filamentous fungi has historically been enigmatic, almost a black box with a very high efficiency [25]. In our research we have obtained new insight in a specific case, i.e. IA production in Aspergillus niger. As already suggested earlier $[8,9]$ we have further confirmed that the three genes of the IA gene cluster in A. terreus all contribute to the efficiency of IA production in the heterologous host $A$. niger. Expression of only the $m t t A$ and $m f s A$ gene in a $c a d A$ expression parental strain resulted in increased levels of $C A$, whereas expression of only $m t t A$ also resulted in increased levels of cis-aconitic acid in the extracellular medium [26]. These results show that uncoordinated expression of these transporters result in secretion of cis-aconitic acid, possibly relieving cytosolic accumulation of unwanted IA pathway intermediates. In addition, a role for MttA in mitochondrial transport of (cis-)aconitic acid is suggested. Based on the fact that at least three distinct classes of transformants are observed, we obtained further confirmation that a correct balance between mitochondrial transport of precursor molecules and cytosolic export of IA is required to establish the most efficient pathway towards IA. Expressing all three genes in the apparently correct levels resulted in the highest titer of IA and reduced titers of CA (Fig. 2a, b; Table 3). In these selected transformants overexpressing the entire IA gene cluster we also observed reduced glucose consumption and reduced biomass formation of high IA producing strains during the end of the fermentation (Fig. 3). As shown in Fig. 4 this is probably due to growth inhibition by IA itself as in the presence of $10 \mathrm{~g} / \mathrm{L}$ IA $A$. niger shows relevant growth inhibition. Obviously (weak) organic acid toxicity is a well-known phenomenon in inhibiting fungal growth [27]. The effect of IA production on growth of A. niger was further analysed using transcriptome analysis (Hossain et al. in prep).

Recently Chen et al. have elucidated a IA degradation pathway in the natural producer A. terreus that metabolizes IA into the building block chemicals acetyl-CoA and pyruvate [28]. This pathway bears remarkable similarity with the IA detoxification pathway identified in the pathogenic species Pseudomonas aeruginosa and Yersinia pestis by Sasikaran et al. [29]. Until now such IA 


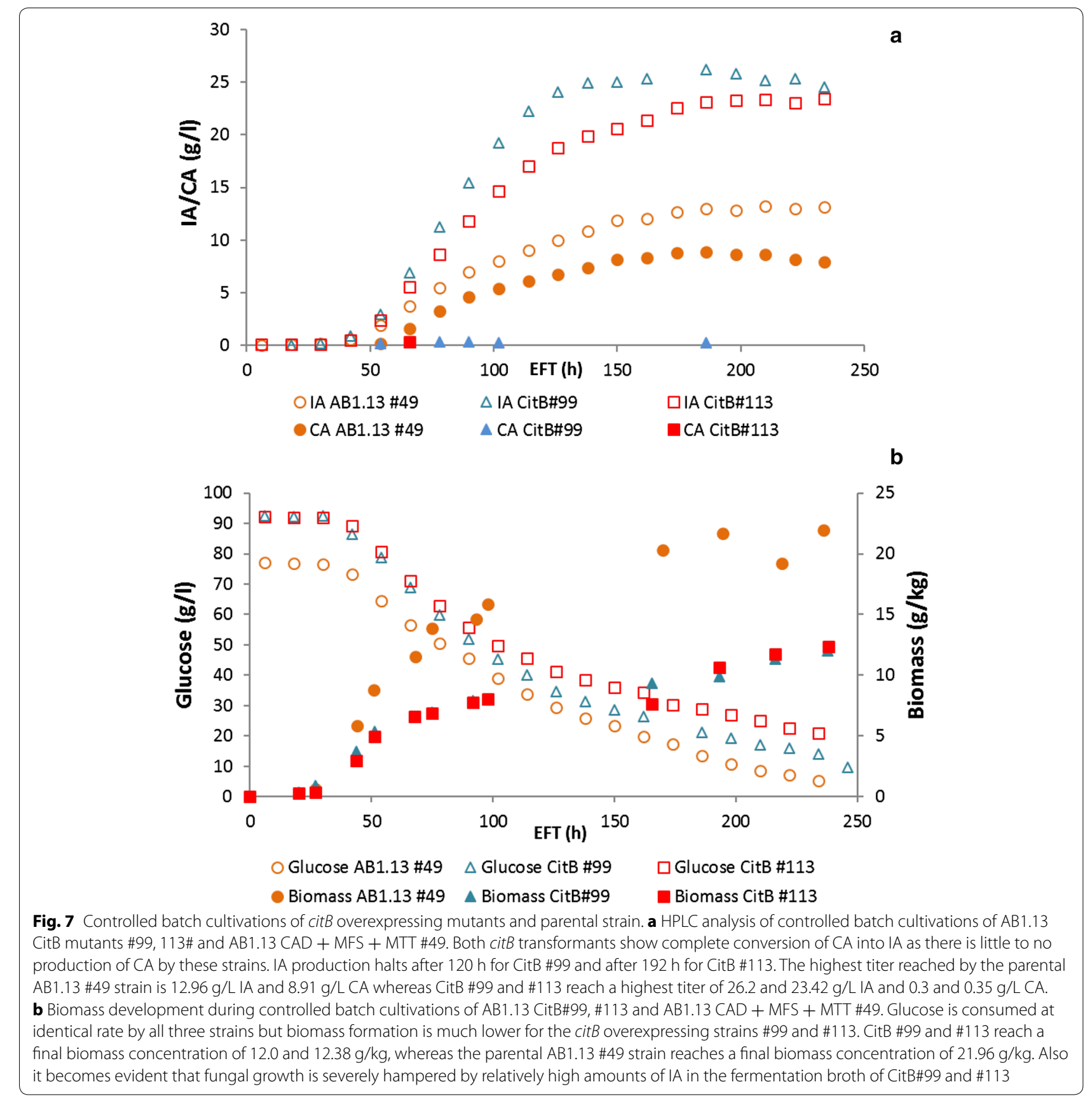

detoxification pathway has not been characterized for $A$. niger, however, this will be further addressed in our ongoing research to improve IA levels.

In a preliminary analysis of the expression profile of a selection of genes related to organic acid production (Additional file 1), we observed a very significant overexpression of two $A$. niger genes, one encoding a citrate synthase and one encoding a CAD-like protein. Both genes are members of a larger gene cluster encoding a secondary metabolite possibly related to IA (Palys et al. manuscript in preparation). Interestingly, in contrast to the canonical citrate synthase CitA this novel citrate synthase, now termed CitB, has no mitochondrial targeting sequence. In an attempt to improve IA production, Blumhoff et al. [30], addressed the aspect that the native pathway in A. terreus was considered to take place in two compartments, i.e. the mitochondrion (citrate synthase and aconitase) and the cytosol (cis-aconitate decarboxylase) [31]. Expression of the aconitase and cis-aconitate decarboxylase genes in either the mitochondrion or 


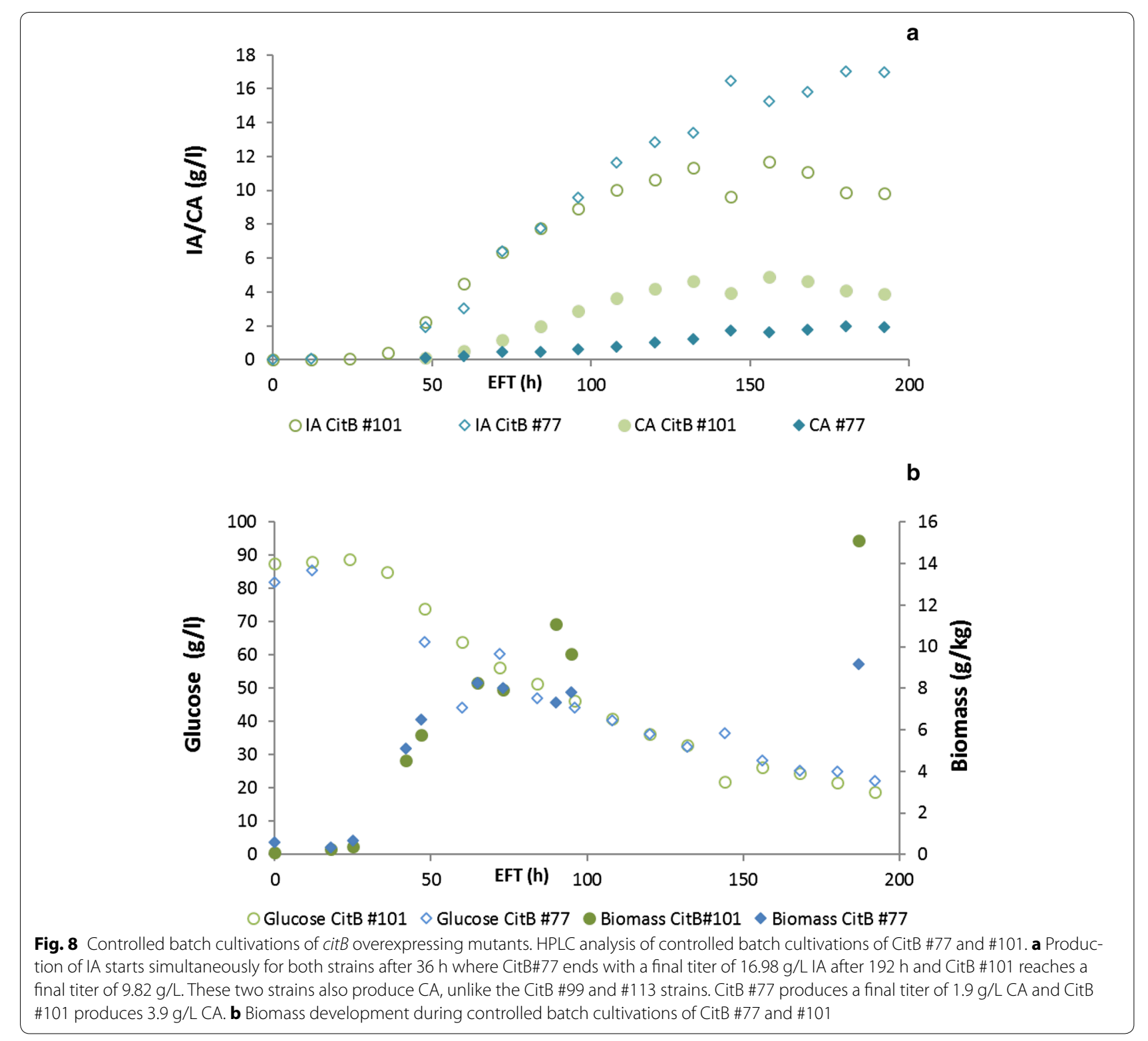

the cytosol resulted in improved IA levels in all cases [30]. The finding of a putative cytosolic citrate synthase allowed us to design a non-mitochondrial biosynthetic pathway by overexpression of the citB gene in a strain expressing the IA gene cluster (Fig. 9). As shown in Fig. 6, overexpression of $c i t B$ resulted in significant increase in IA titers. Moreover, hardly any CA was produced in two of the $c i t B$ overexpressing strains, further demonstrating the positive effect of $c i t B$ overexpression on IA production. It may be somewhat counter intuitive to observe that the overexpression of a citrate synthase would lead to a reduction in CA titer. However, as we show, this reduction in CA titer is accompanied by an increase in IA titer. Therefore we assume that by overexpressing $c i t B$ we have engineered a pathway that enables cytosolic synthesis of citrate and concomitantly its conversion into IA and thus preventing $C A$ to be exported. As shown in Fig. 8 not in all cit $B$ transformants $C A$ production is completely abolished. In controlled batch-cultivations with strains CitB \#77 and \#101 low levels of CA are still observed in the culture medium.

It should be noted that in the classical IA pathway also aconitate dehydratase (or aconitase) activity plays a role, however, none of the aconitate dehydratase-like genes from $A$. niger, apart from the canonical mitochondrial enzyme related to the TCA cycle, was significantly expressed (Additional file 1), raising the question how citrate is converted into cis-aconitate in the cytosol. 


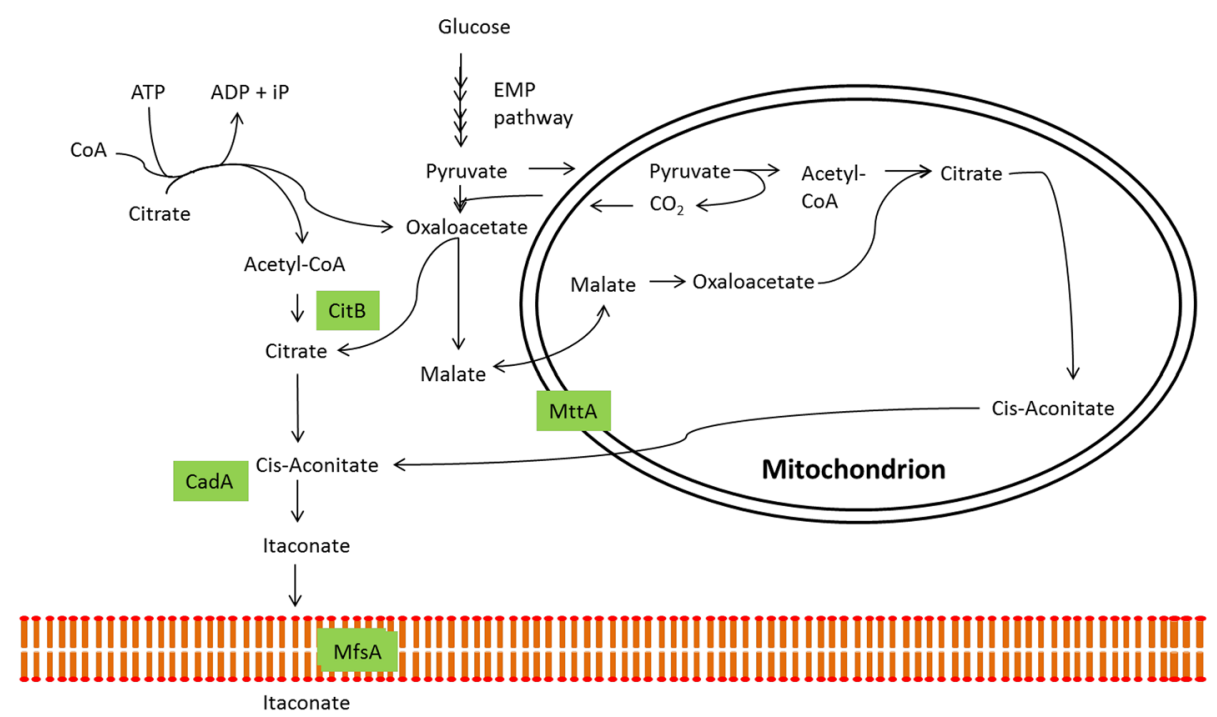

Fig. 9 Hypothetical pathway of itaconic acid production in citB overexpressing A. niger mutants. Hypothetical pathway in citB overexpressing IA producing strains. CitB has no known mitochondrial targeting sequence and is thought to be located in the cytosol where it converts acetyl-CoA and oxaloacetate into citrate. Citrate continues to be further processed by aconitase into cis-aconitate which eventually is decarboxylated by CadA into IA. Theoretically, cis-aconitate shuttling from mitochondria to cytoplasm by MttA is redundant in this novel pathway. Note that only direct pathway steps towards IA production are shown

Table 4 An overview of controlled batch cultivations with IA producing A. niger strains

\begin{tabular}{|c|c|c|c|c|c|c|c|}
\hline \multirow[t]{2}{*}{ Strain } & \multicolumn{2}{|c|}{ Highest titer $\mathrm{g} / \mathrm{L}$} & \multicolumn{2}{|c|}{ Max productivity g/L/h } & \multicolumn{3}{|c|}{ Yield g/g glucose } \\
\hline & Itaconate & Citrate & Itaconate & Citrate & Itaconate & Citrate & Biomass $(\mathrm{g} / \mathrm{kg})$ \\
\hline AB1.13 CAD 4.1 & 1.45 & 15.95 & 0.01 & 0.19 & 0.02 & 0.22 & 17.33 \\
\hline AB1.13 CAD + MFS 3.9 & 1.36 & 4.19 & 0.02 & 0.09 & 0.04 & 0.11 & 9.54 \\
\hline$A B 1.13+C A D+M F S+M T T \# 08$ & 2.48 & 21.99 & 0.02 & 0.13 & 0.03 & 0.29 & 15.59 \\
\hline$A B 1.13+C A D+M F S+M T T \# 63$ & 9.52 & 18.03 & 0.05 & 0.11 & 0.13 & 0.24 & 13.53 \\
\hline$A B 1.13+C A D+M F S+M T T \# 49$ & 11.74 & 13.17 & 0.08 & 0.12 & 0.16 & 0.18 & 15.02 \\
\hline$A B 1.13+C A D+M F S+M T T \# 49$ & 12.96 & 8.91 & 0.15 & 0.13 & 0.20 & 0.14 & 21.69 \\
\hline AB1.13 CitB\#77 & 17.02 & 1.96 & 0.16 & 0.02 & 0.28 & 0.03 & 9.18 \\
\hline AB1.13 CitB\#101 & 11.69 & 4.92 & 0.11 & 0.07 & 0.19 & 0.08 & 15.13 \\
\hline AB1.13 CitB\#99 & 26.22 & 0.30 & 0.35 & NA & 0.37 & NA & 9.9 \\
\hline AB1.13 CitB\#113 & 23.42 & 0.35 & 0.26 & NA & 0.33 & NA & 12.38 \\
\hline
\end{tabular}

Overview of titer, productivity and yield of IA and CA during controlled batch-cultivations. Yield and biomass are measuredat point of highest titer. In Fig. 9 an overview of the metabolic pathway consisting of the activities encoded by cadA, citB,mttA and mfs is given

Interestingly, however, members of the gene family encoding CAD like proteins have also been reported to encode citrate dehydratase activity [33]. Therefore we speculate that the $A$. terreus cadA gene and/or the gene encoding the CAD-like protein in the citB gene cluster are able to perform both citrate dehydratase and cisaconitate decarboxylase activity, alleviating the need for a specific aconitate dehydratase protein. Our previous attempts to purify the $A$. terreus CadA protein, had already suggested the presence of a protein with both aconitase and cis-aconitate decarboxylase activity (our unpublished results). In this respect it is also interesting to note that, similar as the IA gene cluster, the $c i t B$ gene cluster does not carry a aconitase encoding gene, while this type of activity would be expected to be required for the production of the pathway specific secondary metabolite [23]. Further biochemical analysis will be required to confirm if the CAD-like proteins in $A$. niger indeed fulfill both steps in the organic acid pathway. Obviously, the idea that CAD-like proteins would fulfill both steps would also be an alternative solution for preventing a futile cycle based on citrate synthase, aconitase and 
ATP-citrate lyase in the same compartment. This may be in particular relevant as recent results have revealed that the mitochondrial tricarboxylic acid transporter MttA, does not export citric acid from the mitochondrion to the cytosol [26]. Whether MttA and endogenous A. niger mitochondrial tricarboxylic acid transporters are still contributing to itaconic acid production in the presence of a cytosolic pathway is currently not known and goes beyond the topic of this paper.

Table 4 summarizes production of various IA producing A.niger strains engineered by us. A clear increase in titer, yield and productivity of IA is seen in $c i t B$ overexpressing strains. Obviously the obtained levels are still below industrial target levels [32]. Therefore, studies to convert industrial CA producing $A$. niger strains into an industrial IA producing strain are underway. These strains can then be fermented under relevant industrial fermentation conditions to obtain the required IA productivity.

It should be noted that our newly designed $c a d A / c i t B$ IA pathway consists of biosynthetic steps derived from two unrelated (secondary metabolite) gene clusters from two different organisms. The IA gene cluster is lacking in $A$. niger, whereas the citB gene cluster is lacking in $A$. terreus. This type of metabolic rewiring and versatility in Aspergillus is not completely unprecedented, as very recently Gou et al. [34] revealed that genes from different metabolite gene clusters can result in partly overlapping biosynthetic pathways.

Interestingly, also a few other fungal species are known to produce IA $[1,35]$. Among these Ustilago maydis is the most well studied species. For this species also the complete genome sequence has been analyzed, allowing to perform genome mining for the presence of the orthologous IA gene cluster. Surprisingly, based on BLAST searches a gene cluster similar to the one observed in A. terreus is not present in Ustilago. However, recently Geiser et al. [24] have shown that in Ustilago IA is naturally produced from a completely different biosynthetic pathway using trans-aconitic acid as precursor, which is synthesized from cis-aconitate via a cis-trans aconitate isomerase. Similar as the IA biosynthetic pathway in $A$. terreus the Ustilago pathway is clustered in the genome together with a mitochondrial transporter and a major facilitator exporter and without any aconitase or aconitate dehydratase. However, none of these transporters are orthologous to those in the A. terreus gene cluster. Based on these results it is clear that the fungal pathways to a relatively simple metabolite like IA show a high level of diversity in different species. By linking parts of the different pathways together we have been able to create a highly efficient pathway with the smallest number of proteins using a two component citrate synthase and citrate dehydratase/cis-aconitate decarboxylase pathway.
One aspect that we have not yet addressed in our research is the origin of the substrate required for the cytosolic citrate synthase. In the mitochondrion the precursors for citrate synthase are oxaloacetate and acetyl-CoA. Oxaloacetate is produced from pyruvate by the action of cytosolic pyruvate carboxylase. There are different mechanisms by which acetyl-CoA can be synthesized in the cytosol $[36,37]$. How these pathways, which are also largely compartmentalized, contribute to the IA production in our strains goes clearly beyond the topic of this paper and is subject of our ongoing research (Hossain et al. in preparation). In our ongoing research these more generic aspects of itaconic acid biosynthesis will be addressed [34, 35]. How these pathways, which are also largely compartmentalized, contribute to the IA production in our strains goes clearly beyond the topic of this paper and is subject of our ongoing research (Hossain et al. in preparation).

\section{Conclusions}

Previously we have reported the stable expression of $\operatorname{cadA}$ in AB1.13 which resulted in low level IA production. Strains carrying a $c a d A+m t t A$ and $c a d A+m f s A$ background performed better than strains carrying only cadA. Engineering of strains that carried the full cluster resulted in higher productivity, yield and titer of IA. However, our results showed that IA production has a negative growth effect on $A$. niger. In order to understand what effect the production of this novel metabolite could have on $A$. niger metabolism we performed an RNA-Seq analysis on shake flask grown cultures of AB1.13 WT and AB1.13 CAD. Interestingly, preliminary analysis of the RNA-Seq data showed induction of a putative cytosolic citrate synthase $c i t B$ that belongs to a secondary metabolite cluster that is hypothesized to be involved in the production of alkylated derivatives of IA. We overexpressed citB in AB1.13 \#49 strains which carries the full IA biosynthesis cluster and by doing so we have reached IA titers up to $26.2 \mathrm{~g} / \mathrm{L}$ in controlled batch-cultivations at a max production rate of $0.35 \mathrm{~g} / \mathrm{L} / \mathrm{h}$ and no detection of side product formation. Studies to integrate this novel IA production pathway in an industrial $C A$ producing $A$. niger strain with the aim to convert it into an industrial IA producing strain are underway.

\section{Additional file}

Additional file 1: Figure S1. Comparison of differentially annotated sequence of MfsA; Table S1. RNA-Seq data of genes involved in organic acid biosynthesis; Table S2. RNA-Seq data of secondary metabolite cluster that is upregulated in itaconic acid producing conditions; Figure S2. Protein sequence comparison of CitA and CitB from Aspergillus niger; Table S3. RNA-Seq data of known prpD-like genes in Aspergillus niger; Table S4. Orthologues of tad1 and adil of Ustilago maydis in Aspergillus niger. 


\section{Abbreviations}

CAD: cis-aconitate decarboxylase; MTT: mitochondrial tricarboxylate transporter; MFS: major facilitator superfamily; CITB: citrate synthase B; WT: wild type; IA: itaconic acid; CA: citric acid.

\section{Authors' contributions}

$\mathrm{AHH}, \mathrm{AL}, \mathrm{AB}$ and $\mathrm{LW}$ performed the experiments; $\mathrm{KO}$ designed the fermentation experiments; MC processed RNA-Seq data; $\mathrm{AHH}$ and PJP wrote the manuscript. All authors read and approved the final manuscript.

\section{Author details \\ 1 Dutch DNA Biotech B.V, Utrechtseweg 48, 3704 HE Zeist, The Netherlands. ${ }^{2}$ Microbiology and Systems Biology, TNO, Utrechtseweg 48, 3704 HE Zeist, The Netherlands. ${ }^{3}$ Molecular Biology and Microbial Food Safety, University of Amsterdam, Science Park 904, 1098 XH Amsterdam, The Netherlands.}

\section{Acknowledgements}

We would like to thank Stanley Brul and Gertien Smits for valuable discussions regarding weak organic acid stress. Heleen de Weerd is acknowledged for her help with RNA-Seq data analysis.

\section{Competing interests}

The authors declare that they have no competing interests.

\section{Availability of data and supporting materials}

The complete RNA-seq data will be published in our follow-up manuscript.

Data is also available upon request.

\section{Consent for publication}

Not applicable.

\section{Ethics approval and consent to participate}

Not applicable.

\section{Funding}

This work was fully funded by Dutch DNA Biotech B.V.

Received: 11 March 2016 Accepted: 20 July 2016

Published online: 28 July 2016

\section{References}

1. Klement T, Büchs J. Itaconic acid - a biotechnological process in change. Bioresour Technol. 2013;135:422-31. doi:10.1016/j.biortech.2012.11.141.

2. Werpy T, Petersen G. Top value added chemicals from biomass. 2004;76.

3. Willke T, Vorlop K-D. Biotechnological production of itaconic acid. Appl Microbiol Biotechnol. 2001:56:289-95.

4. Cordes T, Michelucci A, Hiller K. Itaconic acid: the surprising role of an industrial compound as a mammalian antimicrobial metabolite. Annu Rev Nutr. 2014;35:150514143029003. doi:10.1146/ annurev-nutr-071714-034243.

5. Kuenz A, Gallenmüller Y, Willke T, Vorlop KD. Microbial production of itaconic acid: developing a stable platform for high product concentrations. Appl Microbiol Biotechnol. 2012;96:1209-16.

6. Hevekerl A, Kuenz A, Vorlop K-D. Influence of the $\mathrm{pH}$ on the itaconic acid production with Aspergillus terreus. Appl. Microbiol. Biotechnol. 2014;98:6983-9.

7. Karaffa L, Díaz R, Papp B, Fekete E, Sándor E, Kubicek C. A deficiency of manganese ions in the presence of high sugar concentrations is the critical parameter for achieving high yields of itaconic acid by Aspergillus terreus. Appl Microbiol Biotechnol. 2015. doi:10.1007/s00253-015-6735-6.

8. Li A, van Luijk N, ter Beek M, Caspers M, Punt P, van der Werf M. A clonebased transcriptomics approach for the identification of genes relevant for itaconic acid production in Aspergillus. Fungal Genet Biol. 2011;48:602-11.

9. van der Straat L, Vernooij M, Lammers M, van den Berg W, Schonewille T, Cordewener J, et al. Expression of the Aspergillus terreus itaconic acid biosynthesis cluster in Aspergillus niger. Microb Cell Fact. 2014;13:11. http:// www.pubmedcentral.nih.gov/articlerender.fcgi?artid $=3898256 \&$ tool $=p$ mcentrez\&rendertype $=$ abstract.
10. Steiger MG, Blumhoff ML, Mattanovich D, Sauer M. Biochemistry of microbial itaconic acid production. Front Microbiol. 2013;4:1-5.

11. Li A, Pfelzer N, Zuijderwijk R, Brickwedde A, van Zeijl C, Punt P. Reduced by-product formation and modified oxygen availability improve itaconic acid production in Aspergillus niger. Appl Microbiol Biotechnol. 2013;97:3901-11.

12. Mattern IE, van Noort JM, van den Berg P, Archer DB, Roberts IN, van den Hondel C. Isolation and characterization of mutants of Aspergillus niger deficient in extracellular proteases. Mol Gen Genet. 1992;234:332-6.

13. Li A, Pfelzer N, Zuijderwijk R, Punt P. Enhanced itaconic acid production in Aspergillus niger using genetic modification and medium optimization. BMC Biotechnol. 2012;12:57. http://www.pubmedcentral.nih.gov/articlerender.fcgi?artid $=3472327 \&$ tool=pmcentrez\&rendertype $=$ abstract.

14. Punt PJ, Li A, Caspers M. Novel organic acid pathway. U.S. Patent WO/2014/178717. 2016.

15. Punt PJ, Van Den Hondel CA. Transformation of filamentous fungi based on hygromycin B and phleomycin resistance markers. Methods Enzymol. 1992. p. 447-57.

16. Van Zeijl CMJ, Van De Kamp EHM, Punt PJ, Selten GCM, Hauer B, Van Gorcom RFM, et al. An improved colony-PCR method for filamentous fungi for amplification of pcr-fragments of several kilobases. J Biotechnol. 1998:59:221-4

17. Mortazavi A, Williams B, McCue K, Schaeffer L, Wold B. Mapping and quantifying mammalian transcriptomes by RNA-Seq. Nat Methods. 2008;5:621-8

18. Huang $X$, Lu X, Li Y, Li X, Li J. Improving itaconic acid production through genetic engineering of an industrial Aspergillus terreus strain. Microb Cell Fact. 2014;13(1):1-9.

19. Li A, Punt P. Industrial production of organic acids by fungi. Appl Microb Eng. 2013. doi:10.1201/b15250-3.

20. Pel HJ, de Winde JH, Archer DB, Dyer PS, Hofmann G, Schaap PJ et al. Genome sequencing and analysis of the versatile cell factory Aspergillus niger. Nat Biotechnol. 2007;25:221-31.

21. Andersen MR, Lehmann L, Nielsen J. Systemic analysis of the response of Aspergillus niger to ambient pH. Genome Biol. 2009;10:R47.

22. Frisvad JC, Larsen TO. Chemodiversity in the genus Aspergillus. Appl Microbiol Biotechnol. 2015;99:7859-77.

23. Hasegawa Y, Fukuda T, Hagimori K, Tomoda H, Omura S. Tensyuic acids, new antibiotics produced by Aspergillus niger FKI-2342. Chem Pharm Bull. 2007:55:1338-41.

24. Geiser E, Przybilla SK, Friedrich A, Buckel W, Wierckx N, Blank LM, Bölker M. Ustilago maydis produces itaconic acid via the unusual intermediate trans-aconitate. Microb Biotechnol. 2016;9(1):116-26.

25. Karaffa L, Kubicek CP. Aspergillus niger citric acid accumulation: do we understand this well working black box? Appl Microbiol Biotechnol. 2003;61:189-96.

26. Steiger MG, Punt PJ, Ram AF, Mattanovich D, Sauer M. Characterizing MttA as a mitochondrial cis-aconitic acid transporter by metabolic engineering. Metab Eng. 2016;35:95-104

27. Plumridge A, Hesse SJ, Watson AJ, Lowe KC, Stratford M, Archer DB. The weak acid preservative sorbic acid inhibits conidial germination and mycelial growth of Aspergillus niger through intracellular acidification. Appl Environ Microbiol. 2004;70:3506-11.

28. Chen M, Huang X, Zhong C, Liii J, Luuuu X. Identification of an itaconic acid degrading pathway in itaconic acid producing Aspergillus terreus. Appl Microbiol Biotechnol. 2016. doi:10.1007/s00253-016-7554-0.

29. Sasikaran J, Ziemski M, Zadora PK, Fleig A, Berg I. Bacterial itaconate degradation promotes pathogenicity. Nat Chem Biol. 2014;10:371-7.

30. Blumhoff ML, Steiger MG, Mattanovich D, Sauer M. Targeting enzymes to the right compartment: metabolic engineering for itaconic acid production by Aspergillus niger. Metab Eng. 2013;19:26-32. doi:10.1016/j.ymben.2013.05.003.

31. Jaklitsch WM, Kubicek CP, Scrutton MC. The subcellular organization of itaconate biosynthesis in Aspergillus terreus. J Gen Microbiol. 1991;137:533-9.

32. Project C. Potential for selected platform chemicals. 2011;1-173.

33. Blank L, Green J, Guest JR. AcnC of Escherichia coli is a 2-methylcitrate dehydratase (PrpD) that can use citrate and isocitrate as substrates. Microbiology. 2002;148:133-46.

34. Gou Y, Li J, Zhu J, Xu W, Gao J. Enhancing inulinase yield by irradiation mutation associated with optimization of culture conditions. Br J Microbiol. 2015:46(3):911-20. 
35. Okabe M, Lies D, Kanamasa S, Park EY. Biotechnological production of itaconic acid and its biosynthesis in Aspergillus terreus. Appl Microbiol Biotechnol. 2009;84:597-606.

36. Hynes MJ, Murray SL. ATP-citrate lyase is required for production of cytosolic acetyl coenzyme A and development in Aspergillus nidulans. Eukaryot Cell. 2010;9:1039-48
37. Wynn JP, Hamid A, Midgley M, Ratledge C. Short communication: widespread occurrence of ATP: citrate lyase and carnitine acetyltransferase in filamentous fungi. J Microbiol. 1998;14:145-7.

38. Dereeper A, Guignon V, Blanc G, Audic S, Buffet S, Chevenet F, et al. Phylogeny.fr: robust phylogenetic analysis for the non-specialist. Nucleic Acids Res. 2008;36:465-9.

\section{Submit your next manuscript to BioMed Central and we will help you at every step:}

- We accept pre-submission inquiries

- Our selector tool helps you to find the most relevant journal

- We provide round the clock customer support

- Convenient online submission

- Thorough peer review

- Inclusion in PubMed and all major indexing services

- Maximum visibility for your research

Submit your manuscript at

www.biomedcentral.com/submit 